\title{
OCURRÊNCIA NO BRASIL DA ANOPLOCEPHALA MAGNA (CESTODA-ANOPLOCEPHALIDAE) PARASITA DE EQUÍDEOS" Yaro Ribeiro Gandra
}

2 estampas ( 6 figuras)

Em material colhido em autópsia de um cavalo puro sangue e trazido ao nosso laboratório pelo prof. RENÉ STRAUNARD identificamos alguns exemplares de A. magna. (ABILDGAARD 1789). Por nos parecer esta, a primeira vez que a presença desse cestoide é assinalada no Brasil, achamos interessante redescrevê-lo, por não ser sua literatura facilmente reunida. O único cestoide de cavalo assinalado entre nós é a $A$. perfoliata.

Para isso dispunhamos de 4 exemplares de A. magna colhidos na luz do intestino delgado de um cavalo "puro sangue" de 6 anos e meio, nascido em Santo André, município de São Paulo. Dos 4 exemplares, apenas 2 lectotipos foram usados para preparações histológicas e montagem (Carmim). Os 2 restantes foram guardados como paralectotipos.

A Anoplocephala magna (ABG. 1789), o maior cestoide do cavalo, diferencia-se macroscopicamente da $A$. perfoliata, por ser mais longa e por seus proglótides apresentarem-se menos imbricados que nesta, (Fig. 5). O comprimento varia muito. ScheIBEL da-lhe como média $500 \mathrm{~mm}$. de comprimento, enquanto que NEUMANN $80 \mathrm{~mm}$. e já ABILDGAARD refere $650-750 \mathrm{~mm}$. Nos 4 homeotipos que possuimos o comprimento total variava de $150-200 \mathrm{~mm}$.

Devemos dizer porem que o cestoide em questão possue seus proglótides fracamente ligados entre sí, destacando-se da cadeia com facilidade principalmente os mais posteriores. A largura é mínima logo depois do escolex, torna-se máxima na união dos $2 / 3$ anteriores com o terço posterior, onde pudemos medir $13-20 \mathrm{~mm}$.

O maior comprimento dos proglótides foi observado nos últimos aneis, onde alcançou 2,55 mm.. Esta cifra, entretanto, decresce progressivamente, à medida que nos aproximamos da extremidade anterior.

Percorrendo os bordos laterais dos aneis notamos 2 canais excretores: 1 ventral e 1 dorsal, para cada bordo.

(*) Apresentado ao $2{ }^{\circ}$ Congresso Brasileiro de Veterinaria, Belo Horizonte, 7 a 12-9-1943. 
O escolex é globoso medindo transversalmente 3,404-4,040 mm., sendo êste diâmetro aproximadamente o dobro do diâmetro dorsoventral.

Possue 4 ventosas globosas, desarmadas e com uma parede fortemente muscular, com uma espessura, em média, de 250 micra. O diâmetro transversal maior de cada ventosa mede 1,55-1,71 mm. Sua profundidade chega a atingir $1 \mathrm{~mm}$. (Fig. 4).

Encontramos com muita frequência nos 4 exemplares, aneis anômalos encaixados entre os normais. Estas anormalidades consistiam em: aneis incompletos, bolsa do cirro comum a dois proglótides e outras. Os poros genitais sucedem-se regularmente no mesmo lado do estrobile e cada um faz geralmente uma forte saliência para o exterior, fato que é raro nos aneis jovens.

No atrio genital vem abrir-se a bolsa do cirro e mais posteriormente o canal vaginal. E' frequente observar-se o cirro protaído. A bolsa do cirro é volumosa e característica. Seu tamanho aumenta a medida que se caminha para os aneis posteriores do cestoide; apresenta-se sob forma de uma garrafa cuja parte mais estreita começa no atrio genital e o fundo se dirige para o bordo anterior do anel. 0 comprimento da bolsa do cirro varia de 949-1.818 micra. Seu diâmetro maior, mede 230-411 micra. As paredes da bolsa do cirro são grossas e podemos notar duas regióes, sendo a externa a mais densa. Internamente é revestida por uma camada de células cutículares. Ao fundo da bolsa do cirro vem ter o canal deferente, que antes de atingí-la dilata-se constituindo a vesícula seminal. Esta acha-se sempre junto do bordo anterior do anel. O tamanho desta vesícula varia muito, tornando-se, às vezes, mais volumosa que a própria bolsa do cirro; outras vezes é difícil de ser notada, devido ao seu diâmetro reduzido. Seu tamanho depende diretamente do momento funcional do órgão. Quando repleta apresenta extremidades sinuosas.

$\mathrm{O}$ cirro quando protraído apresenta-se frequentemente enrolado e possue no seu interior um canal, continuação do canal deferente, limitado por fortes paredes. Sua superfície externa mostra-se regularmente coberta por um verdadeiro manto de pequenos espinhos com ápices voltados para a base.

Os testículos acham-se distribuidos por quasi todo o anel e, sob forma de corpúsculos arredondados, abrangem uma área que, atingindo a da bolsa do cirro, vai cobrir até a região dos vasos excretores do lado oposto. Estão colocados no dorso do anel. As esférulas testiculares possuem diâmetros que oscilam entre 57-123 micra, possuem, no seu interior, células de citoplasma corado em azul de vários tons 
(H. E.) e de núcleo vesiculoso com 8 micra de diâmetro, apresentandose geralmente com grandes cromozomas facilmente visíveis no seu interior. Cada testículo é envolvido por uma membrana delicada que o individualiza.

A área ovariana bem menos extensa que a testicular, não alcança a região dos canais excretores e no bordo poral atinge, apenas, a extremidade interna da vesícula seminal.

A glândula ovariana apresenta ramos curtos, digitiformes. Está colocada ventralmente, junto à zona da musculatura transversa da parede do anel. Microscopicamente o ovário apresenta-se cheio de pequenas células que medem cerca de 20 micra, de núcleo vesiculoso (12 micra), de citoplasma basófilo granuloso. Pode-se notar, com facilidade, um nucléolo central.

A glândula vitelínica está desviada para o bordo poral não atingindo a área dos canais excretores. Esta glâdula é constituida por numerosos lóbulos e disposta transversalmente na base do proglótide, atingindo uma área que varia de 1,360-3,00 mm. Está situada entre o receptáculo seminal e o ovário. Nos seus lóbulos notamos numerosas células de núcleos acentuadamente basófilos, células estas cujo tamanho orça pela metade dos óvulos.

A vagina, abrindo-se no atrio genital numa localização posterior à abertura masculina, dirige-se para o centro do anel, beirando o bordo inferior da bolsa do cirro. Nos aneis jovens ela é fina, delicada e sinuosa. Nos aneis maduros, sua função modifica seu aspecto, tornando-a menos sinuosa e mais visível. Em corte que fizemos de aneis já em plena atividade funcional, pudemos medir na vagina uma luz de 100 micra de largura.

Do diâmetro irregular, depois de um percurso de mais ou menos $3 \mathrm{~mm}$., ao nível da área vitelínica, dilata-se muito, para constituir o receptáculo seminal.

O receptáculo seminal é então uma dilatação da vagina e que, quando cheio, se apresenta com uma forma ovoide, cujo diâmetro maior, o transversal, é de até 745 micra. Está localizado na área das glândulas vitelínicas e, em cortes seriados, vimo-lo entre estas ventralmente e algumas vesículas testiculares, dorsalmente.

O útero estende-se transversalmente, no sentido do maior diâmetro do anel. Sua forma e suas dimensões variam, como é natural, com o momento funcional do anel e, portanto, deste orgão. Nos aneis jovens dificilmente êle é identificado, mas nos aneis maduros podemos notar que êle se apresenta sob forma de um tubo mais ou menos retilíneo que percorre a região mediana do proglótide, entre o ovário e as 
vesículas testiculares, estas no seu dorso e, aquele ventralmente. $\mathrm{O}$ tubo uterino nesses aneis, não atinge a área dos canais excretores. Examinando os proglótides mais maduros, verificamos que, à medida que o útero se enche de ovos, começa a emitir grossas ramificações, que se individualisam principalmente para o lado do bordo anterior do anel. Os outros órgãos se atrofiam, o útero se avoluma, chegando, nos aneis grávidos, a tomar quasi toda a dimensão dêstes e atingir, já, a área dos canais excretores. (Fig. 3).

Os ovos tendem para a forma esférica e seu diâmetro varia de 82-91 micra. Devemos assinalar, porém, que não nos foi possível obter nos quatro exemplares que examinamos, ovos com aparelho piriforme já formado.

\section{FIGURAS}
1) Anel maduro
2) Bordo poral
3) Fundo de útero grávido
4) Escolex
5) Fotografia de 2 exemplares
6) Microfotografia de corte transversal
7) Microfotografia de corte transversal

Abreviações - Bc. - bolsa do cirro. C. - cirro. Cd. - canal deferente. V.s. - Vesic. seminal. T. - testículos. Ov. - ovário. Vg. - vagina. R.s. recp. seminal. C.e. - canal excretor. U. - útero. Vi. - glândulas vitelinas. V. - ventosas.

\section{BIBLIOGRAFIA}

BAEr, J. G. - 1927 - Monographie des cestodes de la famille des Anoplocephalidae. Suppl. Bull. Biologique France, 10.

BAYLIS, H. A. - 1929 - A manual of Helminthology, medical and veterinary. New York, William Wood and Company, 1929.

Becker, R. - 1921 - Die äussere Gestallt der Pferdebandwürmer. Centralbl. f. Bakt. u. Parasit. Orig., 87: 110-18.

BECKer, R. - 1922 - De Genitalapparat der Pferdebandwürmer. Centralbl. $f$. Bakt. u. Parasit. Orig., 88: 483-501.

Douthiтr, H. - 1915 - Studies on the Cestode family Anoplocephalidae. Illinois biological monographs, 1 (3).

MöNNIG, H. O. - 1934 - Veterinary Helminthology and Entomology. London, Baillière, Tindall \& Cox.

Neveu-Lemaire, M. - 1936 - Traité d'Helminthologie médicale et vétérinaire. Paris, Vigot frères.

Prnto, C. - 1938 - Zooparasitos de interesse médico e veterinário. Rio de Janeiro, Pimenta de Mello \& Cia.

Pinto, C. - Lins de Almeida J. - 1937 - Sinopsis des helminthes parasites des animaux domestiques du Brésil. in Papers on Helminthology, commemoration 30 year jubileum K. J. Skrjabin, 50th anniversary All-Union Institute of Helminthology: 469-82. Moscow, All-Union Lenin Academy of Agricultural Sciences. 
Y. R. Gandra, Ocurrência no

Brasil da Anoplocephala magna
Rev. Fac, Med. Vet, S. Paulo, Vol, 2, fase. 3

Estampa I
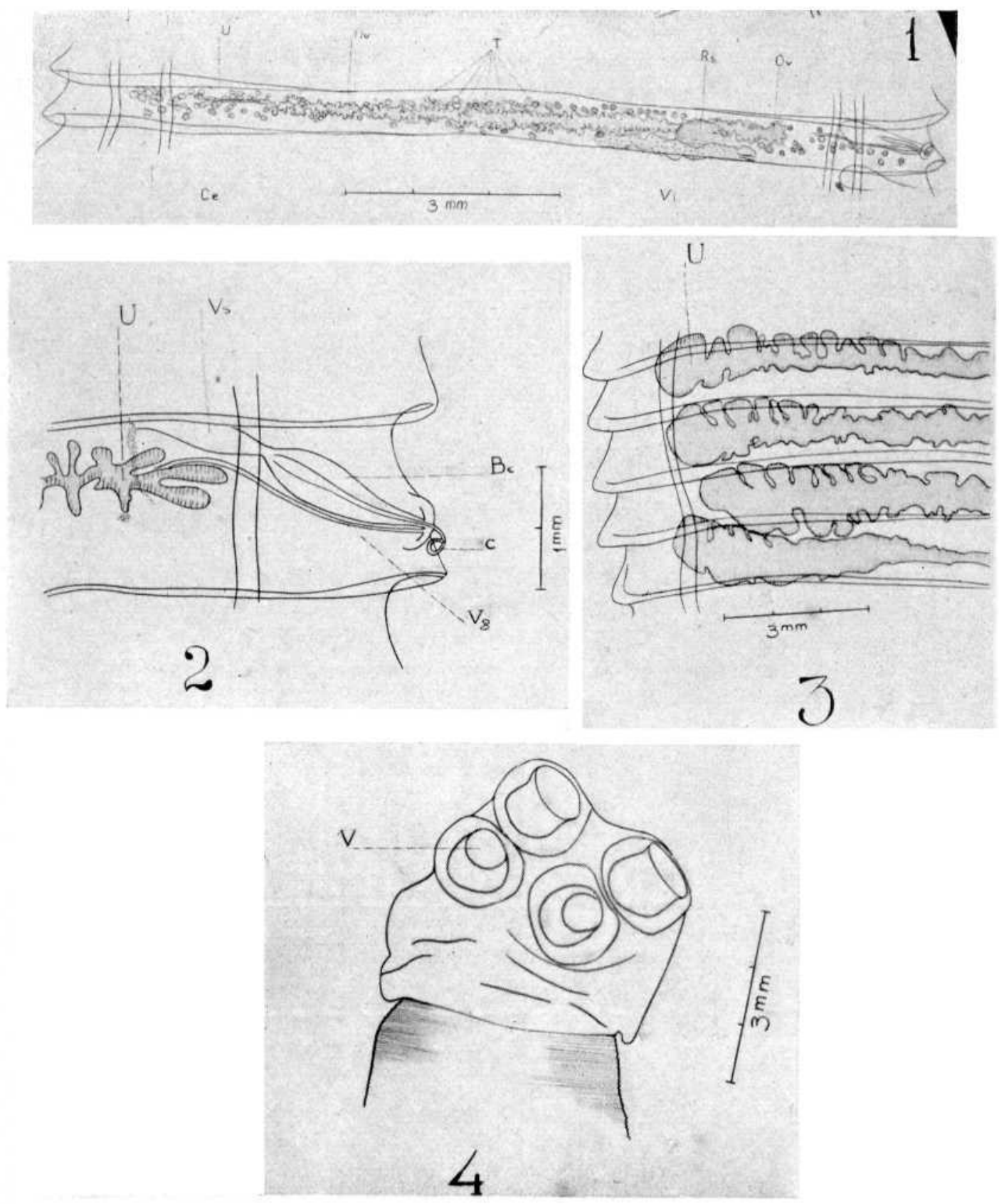
$Y$. R. Gandra, Ocurrência no

Brasil da Anoplocephala magna
Rev. Fac. Med. Vet. S. Paulo, Vol. 2, fasc. $s$

Estampa II
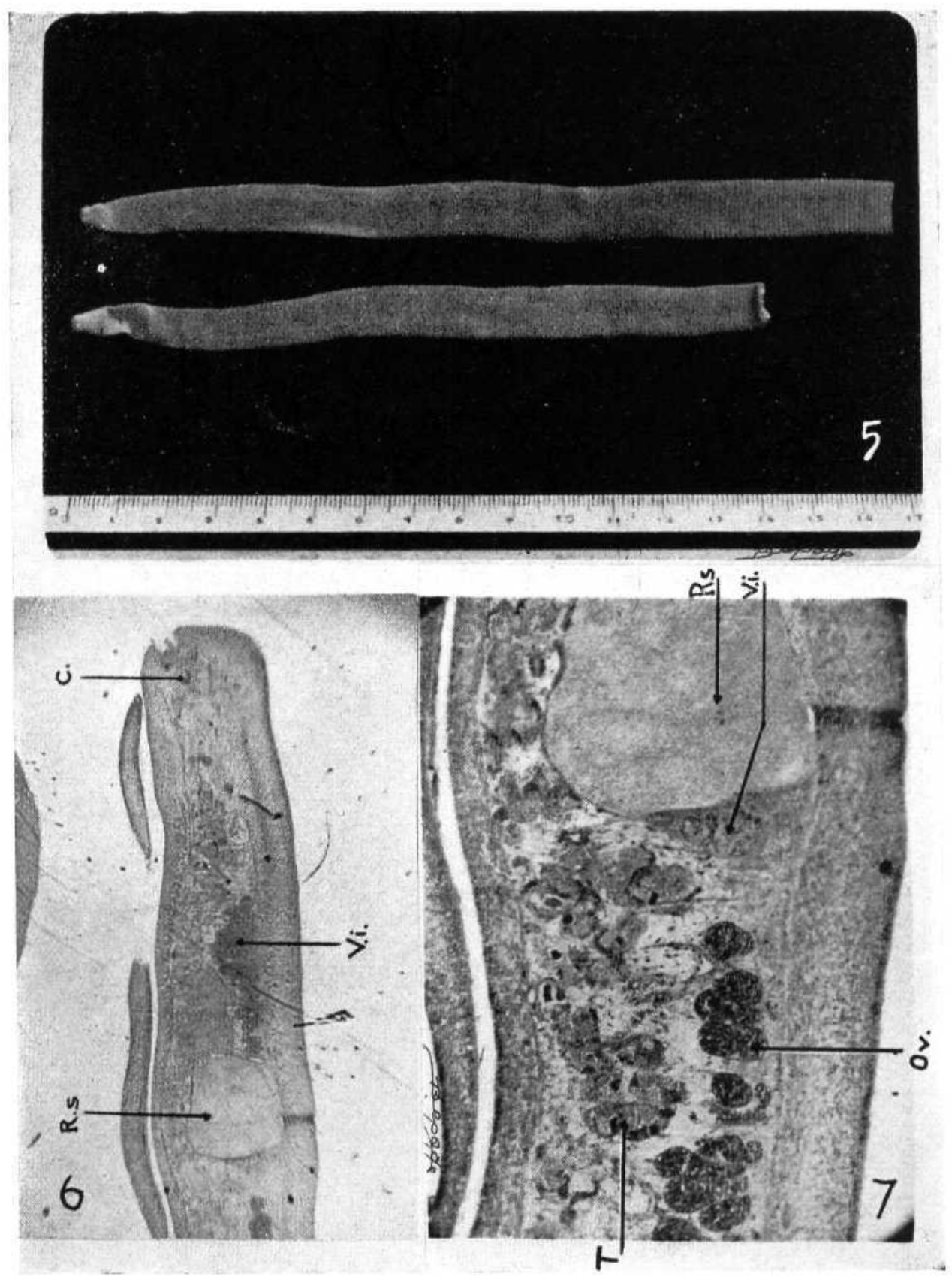